\title{
Tranexamic Acid To Reduce Bleeding after Dental Extraction in Patients Treated with Non- vitamin K Oral Anticoagulants: Design and Rationale of the EXTRACT-NOAC Trial
}

\author{
Authors \\ Anna Ockerman ${ }^{1}$, Maarten Vanhaverbeke ${ }^{2}$, Isabel Miclotte ${ }^{3}$, Ann Belmans ${ }^{4}$, Thomas Vanassche ${ }^{2}$, \\ Constantinus Politis ${ }^{3}$, Reinhilde Jacobs ${ }^{1,5}$, Peter Verhamme ${ }^{2}$ \\ ${ }^{1}$ Oral and Maxillofacial Surgery - Imaging and Pathology research group, Department of Imaging and \\ Pathology, Faculty of Medicine, University of Leuven and Department of Oral \& Maxillofacial Surgery, \\ University of Leuven, Leuven, Belgium. \\ ${ }^{2}$ Department of Cardiovascular Sciences, University of Leuven, Leuven, Belgium. \\ ${ }^{3}$ Department of Oral \& Maxillofacial Surgery, University of Leuven, Leuven, Belgium. \\ ${ }^{4}$ Leuven Biostatistics and Statistical Bioinformatics Centre, Department of Public Health and Primary \\ Care, University of Leuven, Leuven, Belgium. \\ ${ }^{5}$ Department of Dental Medicine, Karolinska Institutet, Stockholm, Sweden.
}

\begin{abstract}
Objectives: Bleeding after dental extraction in patients treated with non-vitamin $\mathrm{K}$ oral anticoagulants (NOACs) may lead to unplanned reinterventions and interruption of the anticoagulation, thereby exposing patients to a thromboembolic risk. We designed a study to investigate whether tranexamic acid (TXA) mouthwash decreases postextraction bleeding in patients treated with NOACs.
\end{abstract}

Patients and methods: The EXTRACT-NOAC study is a prospective, multicentre, randomized, doubleblinded, placebo-controlled trial. Patients treated with NOACs and scheduled for dental extraction, above the age of 18, are eligible. Patients are randomised to 10\% TXA mouthwash or placebo mouthwash. Patients are instructed to use the mouthwash prior to the dental extraction, and thereafter three times a day for three days. The primary outcome of the study is the occurrence of any oral bleeding. Secondary outcomes include subtype of bleeding (minor or clinically relevant bleeds, early or delayed bleeds), procedural bleeding score, number of reinterventions following oral bleeding and number of NOAC therapy interruptions. Any non-oral bleeding and thrombotic events are recorded as safety outcomes. Patients are followed-up for seven days.

Discussion: This randomized study will provide much needed evidence to guide the periprocedural management of patients on NOACs undergoing dental extraction. 


\section{Introduction}

Bleeding is a common complication after dental extraction in patients treated with oral anticoagulants, such as vitamin $\mathrm{K}$ antagonists (VKAs) and non-vitamin $\mathrm{K}$ oral anticoagulants (NOACs) (1). To prevent bleeding, oral anticoagulants can be interrupted prior to dental procedures. In addition, bleeding events may also lead to unscheduled interruption of an anticoagulant therapy. Temporary interruption of oral anticoagulants confers a risk of thromboembolic events, though (2)(3). Therefore, an optimal oral anticoagulant management is crucial to balance the risk of bleeding and the risk of thromboembolism.

Managing VKAs is not simple because these drugs have a long half-life, quite some drug interactions and are influenced by dietary vitamin $\mathrm{K}$ intake. Therefore, routine coagulation monitoring of patients taking VKAs is required. For patients undergoing dental extraction, it is current practice to continue VKAs provided the international normalized ratio (INR) is within the therapeutic range, as this confers no increased risk of bleeding compared to discontinuing or altering the dose of VKAs (4).

Since the introduction of NOACs, the number of patients treated with this class of oral anticoagulants is steadily increasing. The perioperative management of patients on NOACs is easier than with VKAs, because of the shorter half-life of NOACs. However, the risk of mucosal bleeding is higher in patients taking NOACs compared to VKAs (5)(6). Postextraction bleeding is a particular concern in NOACtreated patients, because the oral mucosa is damaged during dental extraction. To minimize the risk of bleeding, the European Hearth Rhythm Association advices to plan dental extraction at trough level of the NOAC. This recommendation can be brought into practice by letting the patients skip a NOAC dose on the morning of dental extraction. With this approach, the risk of early postextraction bleeding is similar between NOAC-treated and non-anticoagulated patients, but the risk of delayed bleeding is still higher for NOAC-treated patients (7). The question thus remains how to reduce the risk of delayed bleeding in patients on NOACs.

Besides the management of oral anticoagulants, haemostatic methods are essential to minimize bleeding. Tranexamic acid (TXA) is an attractive haemostatic agent for local application during dental procedures because of its high efficacy in reducing bleeding and its low systemic absorption (8)(9). The use TXA mouthwash effectively decreases bleeding after dental extraction in patients treated with VKAs (10)(11). Its use in NOAC-treated patients, however, has not yet been studied. Therefore, this interventional study is set-up to assess whether TXA mouthwash reduces bleeding after dental extraction in patients on NOACs.

\section{Patients and methods}

The EXTRACT-NOAC study is a prospective, randomized, double-blinded, placebo-controlled, multicentre, investigator-initiated, clinical trial (ClinicalTrials.gov ID: NCT03413891). The Medical Ethics Committee Research UZ/KU Leuven approved the study in July 2017. Recruitment started in February 2018.

\section{Patients and randomisation}


Patients treated with a NOAC (edoxaban, apixaban, rivaroxaban or dabigatran) who are scheduled for dental extraction and are older than 18 years are eligible. Exclusion criteria include pregnancy, lactation or any condition resulting in increased risk of harm in case of participation (Table 1). Subjects provide informed consent prior to any study-related procedures. Patients are randomised via an interactive web response system to TXA mouthwash or to placebo mouthwash. The study is blinded to both the patient and treating surgeon and investigator.

Table 1: Inclusion and exclusion criteria of the EXTRACT-NOAC trial

\begin{tabular}{|c|c|}
\hline Inclusion criteria & Exclusion criteria \\
\hline$\geq 18$ years & $<18$ years \\
\hline Scheduled for dental extraction & Known allergic reaction to TXA \\
\hline $\begin{array}{c}\text { Treated with a NOAC: edoxaban, apixaban, } \\
\text { rivaroxaban or dabigatran }\end{array}$ & Pregnancy or lactation \\
\hline $\begin{array}{l}\text { No morning NOAC dose on the day of dental } \\
\text { extraction }\end{array}$ & $\begin{array}{l}\text { Suffering from any condition that - as judged by } \\
\text { the investigator - would place the subject at } \\
\text { increased risk of harm if he/she participated }\end{array}$ \\
\hline Informed consent & \\
\hline
\end{tabular}

\section{Intervention}

The study drug is $1 \mathrm{~g} / 10 \mathrm{~mL}(10 \%)$ TXA mouthwash or a matching placebo. The mouthwash is packed into oral syringes of ten millilitre. The mouthwash-containing syringes are produced by the Leuven Centre for Clinical Pharmacology, UZ Leuven, Belgium. The placebo mouthwash is composed out of water with $2.5 \mathrm{~mL}$ cherry aroma $(45 \%)$, in order to mimic the taste and odour of TXA mouthwash. Both TXA and placebo mouthwashes are colourless. At randomisation, patients are assigned to a drug kit containing ten syringes of study drug. The first administration of study drug is immediately prior to dental extraction. After dental extraction, the study mouthwash is used three times a day for three days, starting the day after extraction.

\section{Outcomes}

The primary outcome is any oral bleeding that occurs within seven days after dental extraction. Oral bleeding is defined in three categories as previously published (Table 2Fout! Verwijzingsbron niet gevonden.) (7). Major oral bleedings are events requiring blood transfusion, hospitalization or resulting in death. Clinically relevant oral bleedings are non-major oral bleeding complications requiring unplanned medical contact with any health care professional or requiring additional haemostatic measures (except for gauzes), with or without surgical reintervention. A reintervention is defined as any procedure in the oral cavity for the treatment of bleeding, except for rinsing the extraction socket with saline, performed by a dentist or maxillofacial surgeon. Other oral bleeds, such as bleeding requiring the use of additional gauzes, blood on the pillow, clear red bleeding when spitting out the mouthwash, etc. are classified as minor oral bleedings. The primary outcome deliberately includes minor oral bleeding, because these bleeds may lead to NOAC discontinuation and subsequent risk of thromboembolism. Additionally, oral bleeding is also categorised as early or delayed. Early oral bleeding is defined as bleeding events occurring up to 24 hours after extraction. 
Delayed bleeding is defined as any oral bleeding occurring between day 2 and day 7 after the extraction.

Table 2: Definitions of oral bleeding events

\section{Oral Bleeding events}

Subdivided by

\begin{tabular}{|l|l|} 
& Major \\
\hline $\begin{array}{l}\text { Degree of } \\
\text { severity }\end{array}$ & $\begin{array}{l}\text { Clinically relevant } \\
\text { non-major }\end{array}$ \\
\hline
\end{tabular}

Timing

\section{Definition}

Oral bleeding events requiring blood transfusion, hospitalization or resulting in death.

Oral, non-major bleeding events requiring unplanned medical contact or additional haemostatic measures (except for gauzes), with or without surgical reintervention.

Oral bleeding events such as bleeding requiring the use of additional gauzes, blood on the pillow, clear red bleeding when spitting out the mouthwash, etc. Oral bleeding events occurring after the extraction up to and including day 1 after dental extraction.

Oral bleeding events occurring between day 2 and day 7 after dental extraction.

Secondary outcomes include the number of bleeding events in the three oral bleeding categories (minor, clinically relevant and major); early or delayed, the number of reinterventions following oral bleeding and the number of unplanned NOAC interruptions (Table 3). Any non-oral bleeding events and thrombotic events, including myocardial infarction, stroke, systemic embolism and venous thromboembolism, up to the end of the study follow-up, are recorded as safety outcomes.

Table 3: Primary, secondary and safety outcome variables

\section{Outcomes}

\begin{tabular}{|l|l|}
\hline Primary & Any oral bleeding \\
\hline \multirow{3}{*}{ Secondary } & Major oral bleeding \\
\hline & Clinically relevant oral bleeding \\
\hline Minor oral bleeding \\
\hline & Early oral bleeding events \\
\hline & Delayed oral bleeding events \\
\hline & Procedural bleeding score \\
\hline Reinterventions after oral bleeding \\
\hline NOAC therapy interruptions \\
\hline \multirow{2}{*}{ Safety } & Occurrence and number of any non-oral bleeding event \\
\hline & Occurrence and number of any thrombotic event \\
\hline
\end{tabular}




\section{Study procedures}

\section{Periprocedural management}

The perioperative management of patients treated with NOACs is to skip the NOAC dose on the morning of dental extraction, in agreement with the European Heart Rhythm Association (12). After informed consent, demographical data, medical history and data on smoking status, alcohol consumption and concomitant drugs use are recorded.

Immediately prior to dental extraction, patients are instructed to gently rinse the mouth with $10 \mathrm{~mL}$ of $10 \%$ TXA or placebo mouthwash for one minute before spitting it out. During dental extraction, the following information is recorded: indication for extraction, intraprocedural bleeding score (VASscore, ranging from zero to ten), tooth numbers of extracted teeth and surgical techniques. Data on the surgical technique include if there is suturing, burring, use of haemostatics (e.g. surgical sponges) and use of prophylactic oral antibiotics. After dental extraction, patients are monitored for half an hour to assure adequate haemostasis.

\section{Postextraction management and follow-up}

Patients are instructed to gently rinse their mouth with the assigned mouthwash three times a day for three days, starting the day after dental extraction. They also receive instructions on how to stop minor oral bleeding (such as biting on gauze) and are asked to monitor and record any bleeding events. The NOAC is restarted on the first day after dental extraction, unless there are haemostasis issues. Two days and seven days after the dental extraction, patients are contacted by phone by investigators, blinded to the allocated treatment, to assess patients' compliance with the study protocol, occurrence of any oral bleeding and safety outcomes (Figure 1).

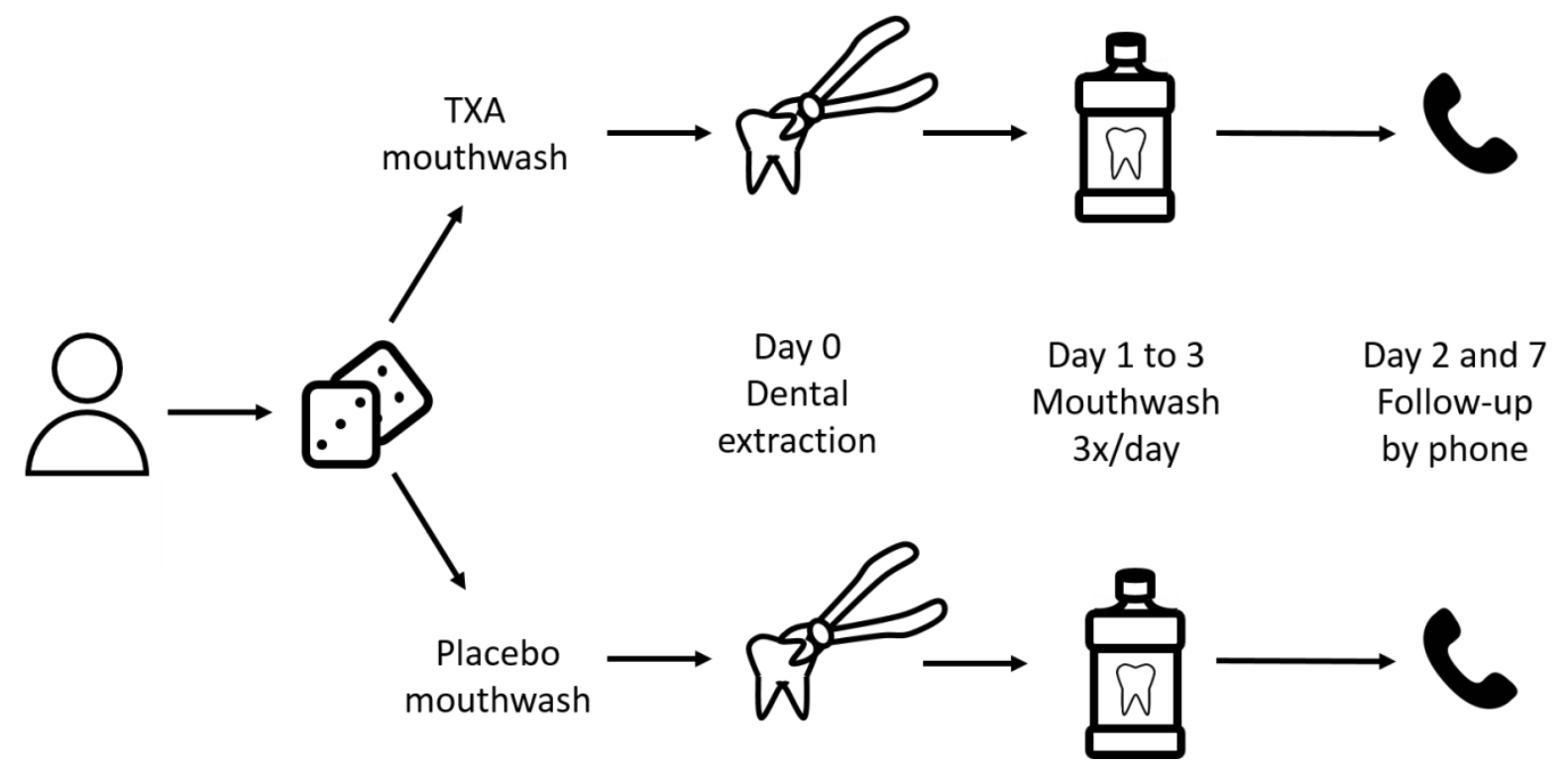

Figure 1: Study design of the EXTRACT-NOAC study. After informed consent, patients are randomised to TXA mouthwash or to placebo mouthwash. The mouthwash is used immediately prior to dental extraction (day 0 ), and after dental extraction three times a day for three days (day 1 to 3). Patients are contacted on day 2 and day 7 after dental extraction to assess all outcomes and compliance. 


\section{Statistical analysis}

This study has a superiority design. The null hypothesis states that there is no difference in any oral bleeding between patients receiving the active TXA mouthwash and the placebo mouthwash. Based on a pilot study on bleeding complications after dental extraction in NOAC-treated patients, the rate of the primary outcome (the occurrence of any oral bleeding event) was estimated to be approximately $30 \%$ in the placebo group (7). Furthermore, we estimated an absolute risk reduction of $15 \%$ in the TXA group, which implies an expected incidence of $15 \%$. In order to detect a statistical significant difference in bleeding risk between the TXA and placebo treatment, 118 patients per group or 236 patients in total are required. The confidence level of the study is set to $95 \%$ and power to $80 \%$.

The primary analysis will consist of the intention-to-treat population, i.e. all randomised patients who received at least one administration of the study mouthwash. In addition, a sensitivity analysis will be performed in the per-protocol population, i.e. all subjects without major protocol deviations who have complied with the assigned treatment for at least $80 \%$. The overall significance level is set at $5 \%$ (two-sided), $p=0.05$.

The primary outcome, i.e. the occurrence of bleeding events up to day seven, will be analysed in terms of a difference in risk between the two treatment groups. The secondary endpoints will be compared using Fisher Exact Test (low number of events) or Chi Square test (high number of events), depending on the number of events.

An interim analysis with blinded sample size re-estimation is planned after 100 included patients. All data regarding the primary endpoint will be passed on to an independent statistician in a blinded manner. The aim of this interim analysis is to estimate the incidence of oral bleeding and to recalculate the sample size based on this newly estimated incidence of oral bleeding.

\section{Discussion}

Bleeding after dental extraction is an important concern for patients taking oral anticoagulants. The optimal management of NOACs to minimize this risk of bleeding is unknown. Furthermore, patients on NOACs may be more prone to postextraction mucosal bleeding compared to patients treated with VKAs (ref). In patients on VKAs, TXA reduces the risk of periprocedural bleeding but data in patients on NOACs are lacking (ref). Therefore, this trial was designed to investigate the efficacy of TXA mouthwash to reduce oral bleeding in patient on NOACs who undergo dental extraction.

\section{Two types of oral anticoagulants}

The most common indications for oral anticoagulants include the prevention of stroke in patients with atrial fibrillation, the treatment and prevention of pulmonary embolism and deep venous thrombosis, and the prevention of mechanical heart valve thrombosis. VKAs were the gold standard for many years, but recently NOACs have become the recommended therapy for most patients with atrial fibrillation (AF) and venous thromboembolism. Four NOACs are currently approved: rivaroxaban (Xarelto ${ }^{\circledR}$ ), apixaban (Eliquis ${ }^{\circledR}$ ), edoxaban (Lixiana ${ }^{\circledR}$ ) and dabigatran (Pradaxa ${ }^{\circledR}$ ) (Table 4) $(13)(14)(15)(16)$. VKAs inhibit the hepatic synthesis of clotting factors II, VII, IX and X, while NOACs 
specifically inhibit factor Xa (rivaroxaban, edoxaban, apixaban) or factor lla (dabigatran). In contrast to VKAs, NOACs have a more rapid onset and offset of action, fewer drug interactions, are not influenced by dietary intake of vitamin $\mathrm{K}$ and do not require routine coagulation monitoring (5).

Table 4: Characteristics of the non-vitamin K oral anticoagulants

\begin{tabular}{|c|c|c|c|c|}
\hline & $\begin{array}{c}\text { Rivaroxaban } \\
\left.\text { (Xarelto }{ }^{\circledR}\right)\end{array}$ & $\begin{array}{l}\text { Apixaban } \\
\text { (Eliquis }{ }^{\circledR} \text { ) }\end{array}$ & $\begin{array}{l}\text { Edoxaban } \\
\left(\text { Lixiana }{ }^{\circledR}\right)\end{array}$ & $\begin{array}{l}\text { Dabigatran } \\
\left(\text { Pradaxa }^{\oplus}\right)\end{array}$ \\
\hline Working mechanism & FXa inhibitor & FXa inhibitor & FXa inhibitor & Flla inhibitor \\
\hline $\begin{array}{l}\text { Standard dose in atrial } \\
\text { fibrillation }\end{array}$ & $20 \mathrm{mg} q d$ & $5 \mathrm{mg}$ bd & $60 \mathrm{mg}$ qd & $150 \mathrm{mg}$ (EU) bd \\
\hline Reduced dose & $15 \mathrm{mg} q d$ & $2.5 \mathrm{mg} \mathrm{bd}$ & $30 \mathrm{mg} q d$ & $110 \mathrm{mg}$ bd \\
\hline Half-life (h) & 5-9 & 12 & $10-14$ & $12-17$ \\
\hline Renal elimination (\%) & 35 & 27 & 35 & 80 \\
\hline
\end{tabular}

$\mathrm{qd}=$ once daily, $\mathrm{bd}=$ twice daily

NOACs are as effective as VKAs in the prevention of stroke in patients with atrial fibrillation, but have a superior overall safety profile (17)(5). A meta-analysis of the ROCKET-AF (rivaraxaban vs warfarin), ARISTOTLE (apixaban versus warfarin), ENGAGE AF-TIMI 48 (edoxaban vs warfarin) and RE-LY (dabigatran vs warfarin) trials, has demonstrated the overall favourable benefit-risk profile of NOACs compared to warfarin (5). The use of NOACs resulted in significant reductions in mortality, stroke and intracranial haemorrhage and a similar rate of major bleeding, but a higher rate of gastrointestinal bleeding, compared to warfarin (5). As for the prevention of stroke and systemic embolism, rivaroxaban and edoxaban were noninferior to warfarin, whereas apixaban and dabigatran were superior. Major bleeding was significantly reduced for patients treated with apixaban and edoxaban, but not for rivaroxaban and dabigatran. Intracranial bleeding was significantly reduced with the use of all four NOACs. Gastrointestinal bleeding, on the other hand, was increased in patients using rivaroxaban and dabigatran (18)(19)(20)(21).

\section{Management of NOACs with dental extraction}

Data on the management of NOACs in patients undergoing dental extraction are limited (22). The European Heart Rhythm Association advices to perform dental extraction at trough NOAC drug level (23)(24). However, it can be complicated to schedule the extraction at the time of the day corresponding to trough plasma levels in clinical practice. A standardized pragmatic approach, i.e. skipping only the NOAC dose on the morning of dental extraction, regardless of timing of extraction, drug regimen or renal function, has been evaluated in a clinical study evolving NOAC-treated and non-anticoagulated patients. (7). There was no difference in the procedural bleeding score or in early bleeding between NOAC-treated patients and non-anticoagulated patients. Nevertheless, delayed bleeding between day one and day seven after extraction occurred more frequently in NOAC-treated patients compared to non-anticoagulated patients. Similarly, an increase in bleeding during the first postoperative week after dental extraction in patients under uninterrupted rivaroxaban was reported in a retrospective study by Hanken et al. (25). Moreover, patients treated with NOACs have a higher susceptibility to mucosal bleeding (6). This is worrying since damaging the oral mucosa during dental extraction is unavoidable. Furthermore, the combination of NOAC peak plasma levels with an immature coagulum at the extraction site can trigger bleeding. Because of both the bleeding 
risk and the thromboembolic risk periprocedurally, an optimal strategy to minimize postextraction bleeding is required (3).

\section{TXA mouthwash to reduce postextraction bleeding}

The EXTRACT-NOAC trial assesses the use of tranexamic acid (TXA) mouthwash to reduce bleeding after dental extraction in patients on NOACs.

TXA is an antifibrinolytic agent that reversibly inhibits plasminogen, preventing plasmin from degrading fibrin. Originally, it was developed for the treatment of haemophilia or other bleeding disorders, and it is also indicated for the treatment of heavy menstrual bleeding. Nowadays, TXA is widely used to manage severely injured trauma patients or patients undergoing surgery at risk for haemorrhage (26)(8). Over time, TXA has also made its entrance in oral surgery, such as dental extractions. A recent systematic review showed the considerable benefit of TXA as local haemostatic agent for patients undergoing dental extraction (10).

Topical administration of TXA mouthwash is of special interest for oral surgery because of low systemic absorption. Systemic administration of $1 \mathrm{~g}$ TXA leads to peak plasma levels of $7 \mu \mathrm{g} / \mathrm{mL}$, without detectable levels in the saliva, while topical administration of $10 \mathrm{~mL} 5 \%$ TXA mouthwash resulted in low plasma levels (below $2 \mu \mathrm{g} / \mathrm{mL}$ ) and therapeutic levels in the saliva (for at least two hours) (27). Consequently, topical TXA is considered safe without evidence for prothrombotic systemic adverse effects (9)(27).

The current trial investigates if a three-day course of TXA reduces the postextraction bleeding rate in patients on NOACs. The reason to opt for a three-day course is dual. First, it has been demonstrated that a two-day and a five-day TXA regimen was equally effective in reducing postextraction bleedings in patients on VKAs (28). A short treatment period is more attractive from an economical point of view than a longer treatment period. Secondly, 10\% TXA mouthwash is available in packages of 10 doses, which is perfectly suitable to implement this strategy into clinical practice: one dose prior to dental extraction, followed by three doses of mouthwash a day for 3 days ( 9 doses). Furthermore, TXA is attractive to prescribe in daily dental practice as this low-cost drug is already on the market. For all these reasons, the efficacy of TXA mouthwash to reduce bleeding after dental extraction requires appropriate investigation in a randomised, placebo-controlled study.

\section{Conclusion}

There is an unmet need for clinical data on how to manage patients on NOACs who undergo dental extraction in order to minimize bleeding. The EXTRACT-NOAC trial investigates if the use of TXA mouthwash reduces postextraction bleeding in these patients. Primary outcome of the trial is oral bleeding, but thromboembolic events are tracked as well. In the end, balancing the risk of bleeding and the risk of thromboembolism is critical. The results of this trial will help to optimize the periprocedural management of NOACs in patients requiring dental surgery. 


\section{Funding and conflicts of interest}

The study is funded through a grant of the Fonds Wetenschappelijk Onderzoek (FWO) (nr grant) and through an ERISTA grant sponsored by Bristol Myers-Squibb (BMS) and Pfizer. 


\section{References}

1. H. II, Y. I, S. A, M. S, G.-Y. Y, H. O, et al. Evaluation of postextraction bleeding incidence to compare patients receiving and not receiving warfarin therapy: a cross-sectional, multicentre, observational study. BMJ Open [Internet]. 2014 Dec;4(12):e005777. Available from: http://www.embase.com/search/results?subaction=viewrecord\&from=export\&id=L60113039 3

2. Douketis JD, Spyropoulos AC, Kaatz S, Becker RC, Caprini JA, Dunn AS, et al. Perioperative Bridging Anticoagulation in Patients with Atrial Fibrillation. N Engl J Med [Internet]. 2015;373(9):823-33. Available from: http://www.nejm.org/doi/10.1056/NEJMoa1501035

3. Sherwood MW, Douketis JD, Patel MR, Piccini JP, Hellkamp AS, Lokhnygina Y, et al. Outcomes of temporary interruption of rivaroxaban compared with warfarin in patients with nonvalvular atrial fibrillation: Results from the rivaroxaban once daily, oral, direct factor Xa Inhibition Compared with Vitamin K Antagonism for Prevention of Stro. Circulation. 2014;129(18):18509.

4. Nematullah A, Alabousi A, Blanas N, Douketis J, Sutherland S. Dental surgery for patients on anticoagulant therapy with warfarin: a systematic review and meta-analysis [Internet]. Vol. 75, Journal of the Canadian Dental Association. 2009. p. 41-41i. Available from: http://onlinelibrary.wiley.com/o/cochrane/cldare/articles/DARE-12009106047/frame.html

5. Ruff CT, Giugliano RP, Braunwald E, Hoffman EB, Deenadayalu N, Ezekowitz MD, et al. Comparison of the efficacy and safety of new oral anticoagulants with warfarin in patients with atrial fibrillation: A meta-analysis of randomised trials. Lancet. 2014;383(9921):955-62.

6. Vanassche T, Hirsh J, Eikelboom JW, Ginsberg JS. Organ-specific bleeding patterns of anticoagulant therapy: Lessons from clinical trials. Thromb Haemost. 2014;112(5):918-23.

7. Miclotte I, Vanhaverbeke M, Agbaje JO, Legrand P, Vanassche T, Verhamme $P$, et al. Pragmatic approach to manage new oral anticoagulants in patients undergoing dental extractions: a prospective case-control study. Clin Oral Investig. 2017;21(7):2183-8.

8. L. T, M. B, E. B. Tranexamic acid - An old drug still going strong and making a revival. Thromb Res [Internet]. 2015;135(2):231-42. Available from:

http://www.embase.com/search/results? subaction=viewrecord\&from=export\&id=L60166050 9

9. Ker K, Beecher D, Roberts I. Topical application of tranexamic acid for the reduction of bleeding. Cochrane Database Syst Rev [Internet]. 2013;(7). Available from:

http://doi.wiley.com/10.1002/14651858.CD010562.pub2

10. Ockerman A, Miclotte I, Vanhaverbeke M, Verhamme P, Poortmans LL, Vanassche T, et al. Local haemostatic measures after tooth removal in patients on antithrombotic therapy: a systematic review. Clin Oral Investig. 2018;

11. Ramström G, Sindet-Pedersen S, Hall G, Blombäck M, Alander U, Ramstrom G, et al. Prevention of postsurgical bleeding in oral surgery using tranexamic acid without dose modification of oral anticoagulants. J oral Maxillofac Surg [Internet]. 1993 Nov;51(11):1211-6. Available from: http://onlinelibrary.wiley.com/o/cochrane/clcentral/articles/963/CN00096963/frame.html

12. Steffel J, Verhamme P, Potpara TS, Albaladejo P, Antz M, Desteghe L, et al. The 2018 European Heart Rhythm Association Practical Guide on the use of non-Vitamin K antagonist oral anticoagulants in patients with atrial fibrillation. Eur Heart J. 2018;39(16):1330-93. 
13. Productkenmerken SVANDE. SMPC rivaroxaban - Xarelto ${ }^{\circledR}$. Available from:

https://www.ema.europa.eu/documents/product-information/xarelto-epar-productinformation_nl.pdf

14. Productkenmerken SV a NDE, Park MS, No L, Bereich M. SMPC apixaban - Eliquis ${ }^{\circledR}$. 2017; (April 2015):1-24.

15. Productkenmerken SV a NDE, Park MS, No L, Bereich M. SMPC edoxaban - Lixiana ${ }^{\circledR}$. 2017;(April 2015):1-24.

16. Productkenmerken SVANDE. SMPC dabigatran - Pradaxa ${ }^{\circledR}$. Available from:

http://ec.europa.eu/health/documents/community-

register/2018/20180607141106/anx_141106_nl.pdf

17. Kim I-S, Kim H-J, Kim T-H, Uhm J-S, Joung B, Lee M-H, et al. Non-vitamin K antagonist oral anticoagulants have better efficacy and equivalent safety compared to warfarin in elderly patients with atrial fibrillation: A systematic review and meta-analysis. J Cardiol [Internet]. 2018;72(2):105-12. Available from:

http://www.sciencedirect.com/science/article/pii/S0914508718300479

18. Jarreau PH, Ph D, Carnielli V, Anker JN Van Den, Ph D, Meisner C, et al. Rivaroxaban versus Warfarin in Nonvalvular Atrial Fibrillation. 2015;1497-506.

19. Kappos L, Radue E-W, O' Connor P, Polman C, Hohlfeld R, Calabresi P, et al. Apixaban versus Warfarin in Patients with Atrial Fibrillation. N Engl J Med. 2010;362(5):387-401.

20. Giugliano RP, Ruff CT, Braunwald E, Murphy SA, Wiviott SD, Halperin JL, et al. Edoxaban versus Warfarin in Patients with Atrial Fibrillation. N Engl J Med [Internet]. 2013;369(22):2093-104. Available from: https://doi.org/10.1056/NEJMoa1310907

21. Connolly SJ, Ezekowitz MD, Yusuf S, Eikelboom J, Oldgren J, Parekh A, et al. Dabigatran versus Warfarin in Patients with Atrial Fibrillation. N Engl J Med [Internet]. 2009;361(12):1139-51. Available from: https://doi.org/10.1056/NEJMoa0905561

22. Johnston S. An evidence summary of the management of patients taking direct oral anticoagulants (DOACs) undergoing dental surgery. Int J Oral Maxillofac Surg [Internet]. 2016;45(5):618-30. Available from: http://dx.doi.org/10.1016/j.ijom.2015.12.010

23. Heidbuchel $\mathrm{H}$, Verhamme $\mathrm{P}$, Alings $\mathrm{M}$, Antz $\mathrm{M}$, Hacke $\mathrm{W}$, Oldgren J, et al. European Heart Rhythm Association Practical Guide on the use of new oral anticoagulants in patients with non-valvular atrial fibrillation. Europace. 2013;15(5):625-51.

24. Heidbuchel H, Verhamme P, Alings M, Antz M, Diener HC, Hacke W, et al. Updated European Heart Rhythm Association Practical Guide on the use of non-Vitamin K antagonist anticoagulants in patients with non-valvular atrial fibrillation. Europace. 2015;17(10):1467507.

25. Hanken H, Grobe A, Heiland M, Smeets R, Kluwe L, Wikner J, et al. Postoperative bleeding risk for oral surgery under continued rivaroxaban anticoagulant therapy. Clin Oral Investig. 2016 Jul;20(6):1279-82.

26. Boling B, Moore K. Tranexamic Acid (TXA) Use in Trauma. J Emerg Nurs [Internet]. 2012;38(5):496-7. Available from: http://dx.doi.org/10.1016/j.jen.2012.06.001

27. Sindet-Pedersen S. Distribution of Tranexamic Acid to Plasma and Saliva After Oral Administration and Mouth Rinsing: A Pharmacokinetic Study. J Clin Pharmacol. 1987;27:10058. 
28. Carter G, Goss A. Tranexamic acid mouthwash - A prospective randomized study of a 2-day regimen vs 5 -day regimen to prevent postoperative bleeding in anticoagulated patients requiring dental extractions. Int J Oral Maxillofac Surg [Internet]. 2003 Oct;32(5):504-7. Available from:

http://www.embase.com/search/results?subaction=viewrecord\&from=export\&id=L38263350 


\section{Language editing:}

- Elsevier:

https://webshop.elsevier.com/languageservices/languageediting/

255 euro

- Enago:

https://www.enago.com/editing-services.htm

price on demand

- Paper True

https://www.papertrue.com/academic-

proofreading?gclid=CjOKCQiA s7fBRDrARIsAGEvF8TKKqe95 HIDmEq g Ne7zZXd4n cg2Mux

yaAq0BwRMSql69ku02noaAohmEALw wcB

120 euro

- Proof-reading-service

https://www.proof-reading-

service.com/en/?gclid=CjOKCQiA s7fBRDrARIsAGEvF8QBe8UoiaiLMbjU4vLce3vc82BTRCBn7K

6fgadk3KOKIhKAfQVmuJEaAjLLEALw wcB

14 euro / 1000 woorden

- Editage:

https://www.editage.com/editing-

services/?top=\&PlacementPage:Homepage\&PlacementButton/Link:Start-with-English-

editing

50euro / 1000 woorden

- Wiley Editing Services

https://wileyeditingservices.com/en/

300 euro (7 dagen)

\section{Journals}

- Design and rationale ...

- Probably no high-impact factor journals

- Maxillofacial journals

- Submission, 5 days 